\title{
Implementasi E-Learning Menggunakan Edmodo bagi Guru-Guru SD Kecamatan Cawas, Klaten
}

\author{
E-Learning Implementation using Edmodo for Elementary School Teachers in Cawas \\ District, Klaten \\ Ibnu Utomo Wahyu Mulyono ${ }^{1}$, Eko Hari Rachmawanto ${ }^{2}$, Ajib Susanto ${ }^{3 *}$, Christy Atika Sari ${ }^{4}$, De Rosal \\ Ignatius Moses ${ }^{5}$, Dwi Puji Prabowo ${ }^{6}$, Dimas Irawan Ihya' ${ }^{6}$ Ulumuddin $^{7}$ \\ 1,2,3,4,5 Teknik Informatika, Fakultas Ilmu Komputer, Universitas Dian Nuswantoro Semarang \\ ${ }^{6,7}$ Desain Komunikaasi Visual, Fakultas Ilmu Komputer, Universitas Dian Nuswantoro Semarang \\ E-mail: ${ }^{1}$ ibnu.utomo.wm@dsn.dinus.ac.id ${ }^{2}$ eko.hari.rachmawanto@dsn.dinus.ac.id, \\ 3*ajib.susanto@dsn.dinus.ac.id, ${ }^{4}$ christy.atika.sari@dsn.dinus.ac.id, ${ }^{5}$ moses@dsn.dinus.ac.id, \\ 6dwi.puji.prabowo@dsn.dinus.ac.id , ${ }^{7}$ dimas.irawan@dsn.dinus.ac.id
}

\begin{abstract}
Abstrak
Perkembangan Information and Communication Technology (ICT) atau Teknologi Informasi dan Komunikasi (TIK) dalam beberapa dekade terakhir berjalan sangat cepat sejalan dengan perkembangan teknologi telekomunikasi, termasuk jaringan komputer. Berbagai kendala dialami guru dalam pembelajara di tingkat SD yang siswanya tergolong generasi $Z$ yang sudah menikmati keajaiban internet, guru dituntut dapat membuat desain instruksional, penguasaan TIK sebagai sumber pembelajaran yang up to date dan juga mampu menciptakan relasi dengan orang tua. Untuk mengatasi hal tersebut diperlukan pembelajaran berbasis e-learning yang mampu merelasikan antara guru-siswa-orangtua dalam meningkatkan proses belajar dengan menggunakan Edmodo. Tujuan e-learning ini agar proses belajar mengajar dapat berjalan lebih efektif dan melibatkan semua pihak terutama guru-siswa-orangtua dan pihak sekolah. Hasil dari pelatihan e-learning dengan Edmodo ini yaitu guru mampu menyajikan materi yang sudah dibuat baik slide, video dan text yang nantinya siswa dan orangtua dapat terlibat, pemberian tugas juga dapat dilakukan secara online sehingga efektifitas proses belajar mengajar sebagai suplemen belajar di kelas dapat dilakukan dengan baik.
\end{abstract}

Kata kunci: E-Learning, Edmodo, Guru, Siswa, Orangtua

\begin{abstract}
The development of Information and Communication Technology (ICT) in the last few decades has been very fast in line with the development of telecommunications technology, including computer networks. Various obstacles experienced by teachers in learning at the elementary level where students are classified as generation $Z$ who already enjoy the wonders of the internet, teachers are required to be able to make instructional designs, mastery of ICT as a source of up to date learning and also able to create relationships with parents. To overcome this we need e-learning based learning that is able to correlate between teacher-student-parent in improving the learning process by using Edmodo. The purpose of this e-learning is that the teaching and learning process can run more effectively and involve all parties, especially teacher-student-parents and the school. The results of this e-learning training with Edmodo are that the teacher is able to present material that has been made both slides, videos and texts that later students and parents can get involved, giving assignments can also be done online so that the effectiveness of the teaching and learning process as a supplement to learning in class can be done well.
\end{abstract}

Keywords: E-Learning, Edmodo, Teacher, Student, Parent 


\section{PENDAHULUAN}

Perkembangan teknologi informasi dan komunikasi (TIK) baik secara langsung maupun tidak langsung sangat mempengaruhi perkembangan pendidikan dan menjadi salah satu kebijakan Departemen Pendidikan Nasional[1] untuk diterapkan dan dikembangkan. Saat ini perkembangan teknologi informasi (TI) atau yang biasa juga disebut sebagai teknologi informasi dan komunikasi (Information and Communicatian Technology/ICT) mengalami percepatan yang luar biasa. Perkembangan ini mempunyai pengaruh yang kuat bukan hanya terhadap teknologi informasi itu sendiri namun juga terhadap totalitas hidup ini. Perkembangan teknologi informasi yang sangat pesat ini membawa dampak yang begitu besar bagi pola hubungan antar individu, antar komunitas, bahkan antar negara atau bangsa.

Pesatnya kemajuan Teknologi Informasi dan Komunikasi (TIK) sekarang ini menuntut adanya transformasi pendidikan hingga jenjang pendidikan dasar (Sekolah Dasar). Salah satunya yaitu penerapan pembelajaran e-learning sebagai upaya meningkatkan mutu pendidikan di Sekolah Dasar[2].

Sekolah Dasar bermutu menurut Direktorat Pendidikan Dasar dan Menengah (Dikdasmen) adalah sekolah yang mampu memfungsikan seluruh komponen-komponen sekolah secara efektif dan efisien dalam upaya mewujudkan proses pembelajaran yang kondusif sehingga tujuan pendidikan tercapai[2]. Menurut Bafadal[3] menyebutkan bahwa Sekolah Dasar yang bermutu baik adalah Sekolah Dasar yang mampu berfungsi sebagai wadah proses edukasi, wadah proses sosialisasi dan wadah proses transformasi.

E-learning merupakan bentuk implementasi dari pembelajaran yang memanfaatkan teknologi dan tidak dibatasi oleh ruang dan waktu baik dilakukan secara bersama (synchronous) maupun tidak bersamaan (asynchronous)[4]. Sedangkan manfaat e-learning mempunyai 4 (empat) hal yang utama : meningkatkan kadar interaksi pembelajaran antara peserta didik dengan guru atau instruktur (enhance interactivity between students and teacher ), memungkinkan terjadinya interaksi pembelajaran dari mana dan kapan saja (time and place flexibility), menjangkau peserta didik dalam cakupan yang luas (potential to reach a global audience), dan mempermudah penyempurnaan dan penyimpanan materi pembelajaran (easy updating of content ss well as archivable capabilities)[5].

Pembelajaran e-learning di sekolah dasar tentu bukan bertujuan untuk menghapus secara total pola pembelajaran konvensional, tetapi untuk memperkuat model belajar melalui pengayaan content dan pengembangan teknologi pendidikan. Di sini memang akan terjadi pergeseran peran guru yang semula sebagai sumber utama informasi dan ilmu pengetahuan kemudian akan berpusat pada siswa[2].

Untuk itu, guru dalam proses pembelajaran yang mengintegrasikan TIK diharapkan dapat berperan sebagai fasilitator, kolaborator, mentor, pelatih, pengarah dan teman belajar serta dapat memberikan pilihan dan tanggung jawab yang besar kepada siswa untuk mengalami peristiwa belajar[6].

Pembelajaran e-learning merupakan sebuah konsekuensi logis dalam pola pembelajaran di Sekolah Dasar seiring kemajuan TIK di era Generasi Z, yaitu orang-orang yang lahir di generasi internet atau generasi yang sudah menikmati keajaiban teknologi usai kelahiran internet.

Generasi Z menurut penelitian McCrindle Research Centre adalah sebagai orang-orang yang lahir pada rentang tahun 1995 sampai 2009[7]. Jadi anak-anak sekolah dasar saat ini merupakan Generasi $\mathrm{Z}$ yang perlu mendapatkan pembelajaran e-learning untuk membentuk siswa yang berkecakapan Abad 21, yaitu 4C (communicative, critical thinking, collaborative and creative $[8]$.

Koordinator Wilayah (Korwil) Pendidikan Kecamatan Cawas, Kabupaten Klaten sebagai instansi yang menaungi Sekolah Dasar (SD) di lingkungan Kecamatan Cawas yang dibagi menjadi daerah binaan (dabin) yang terdiri dari 4 sampai 5 sekolah dasar mempunyai 
tugas salah satunya adalah memberikan pelatihan peningkatan kemampuan bagi tenaga administrasi, guru dan kepala sekolah dalam menggunakan teknologi informasi dan komunikasi dalam upaya peningkatan kemampuan menggunakan teknologi komputer untuk membantu kegiatan / pekerjaan yang berhubungan dengan pelaporan kegiatan sekolah maupun kegiatan harian di sekolah. Berbagai kendala yang dihadapi selain kurang tercukupinya anggaran yang disediakan oleh pemerintah untuk meningkatkan teknologi informasi dan komunikasi, juga kurangnya tenaga yang memberikan pelatihan perkembangan TIK.

Untuk mengatasi hal tersebut di atas diperlukan pelatihan pembelajaran berbasis $e$ learning yang mampu merelasikan antara guru-siswa-orangtua dalam meningkatkan proses belajar dengan menggunakan Edmodo[9][10]. Sehingga dengan e-learning ini proses belajar mengajar dapat berjalan lebih efektif dan melibatkan semua pihak terutama guru-siswa-orangtua dan pihak sekolah. Guru-guru SD se kecamatan Cawas diberikan pelatihan e-learning dengan Edmodo agar guru mampu menyajikan materi yang sudah dibuat baik slide, video dan text yang nantinya siswa dan orangtua dapat terlibat, pemberian tugas juga dapat dilakukan secara online sehingga efektifitas proses belajar mengajar sebagai suplemen belajar di kelas dapat dilakukan dengan baik.

\section{METODE PELAKSANAAN}

Tahapan metode penerapan Facebook Marketplace menggunakan tahapan dari konsep Plan, Do, Check and Act (PDCA)[11] yang merupakan proses yang berkelanjutan untuk perbaikan sistem selanjutnya, yang tahapannya dapat diuraikan sebagai berikut :

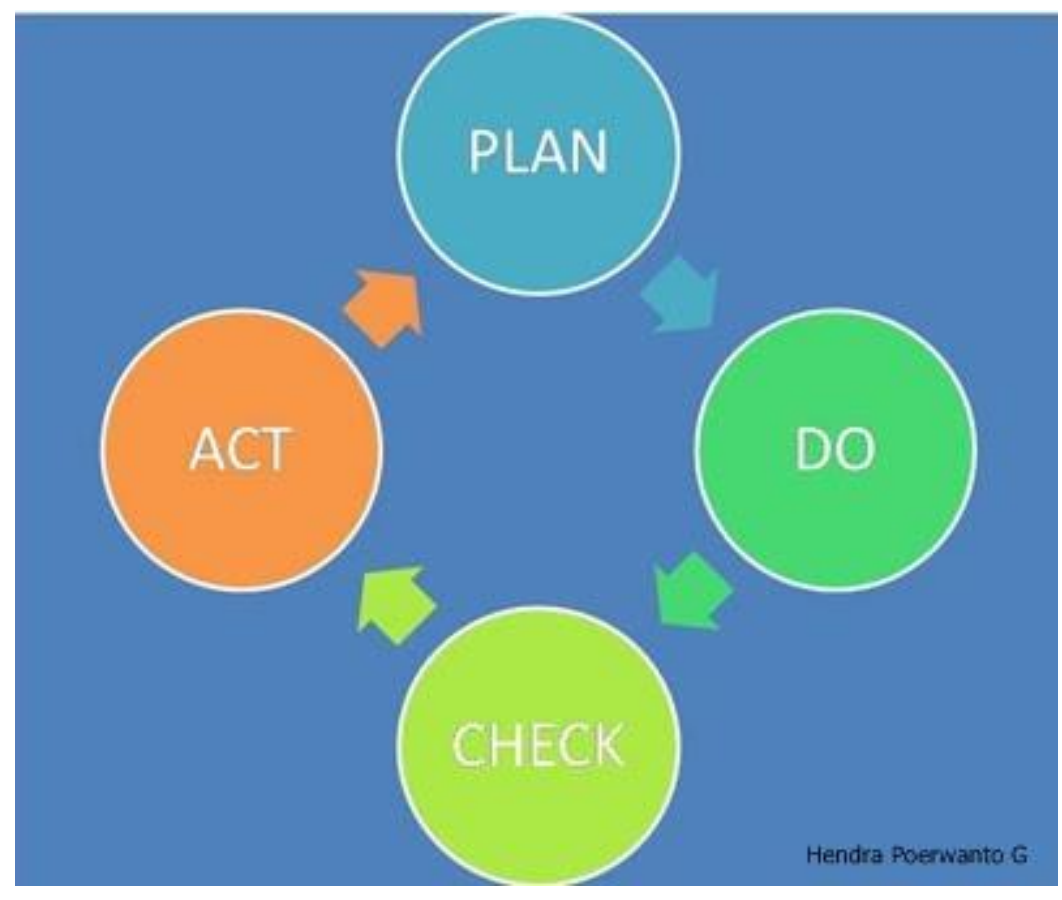

Gambar 1 Konsep PDAC

Konsep P-D-C-A diartikan sebagai proses untuk penyelesaian dan pengendalian masalah dengan model pola secara urut dan sistematis. Lebih jelas proses PDCA dapat diuraikan sebagai

berikut:

\section{1. $\mathrm{P}($ Plan $=$ Rencanakan $)$}

Tahan ini adalah merencanakan tujuan (goal) dan proses apa saja yang dibutuhkan untuk menentukan hasil yang sesuai dengan spesifikasi tujuan yang ditetapkan. Pada tahap ini tujuan 
yang hendak dicapai yaitu membuat pembelajaran e-learning dengan Edmodo yang melibatkan tiga komponen utama yaitu guru, siswa dan orangtua.

2. $\mathrm{D}(\mathrm{Do}=$ Kerjakan $)$

Tahap ini melakukan perencanaan proses yang telah ditetapkan sebelumnya, ukuran-ukuran proses ini juga telah ditetapkan dalam tahap perencanaan. Pada proses ini dihindari penundaan pekerjaan, mulai dari pengumpulan bahan, pembuatan materi ajar, diskusi dengan wali murid dan kelangkapan lainnya. Kemudian dilaksanakan pelatihan e-learning dengan Edmodo untuk mulai membuat akun, unggah materi, membuat kuis dan mengajar siswa dan orangtua membuat akun untuk terlibat di dalamnya.

3.C $($ Check $=$ Evaluasi $)$

Tahap ini melakukan evaluasi terhadap sasaran dan proses serta melaporkan apa saja hasilnya. Mengecek kembali apa yang sudah dikerjakan, sudahkah sesuai dengan standar yang ada atau masih ada kekurangan. Pada tahap ini memantau perkembangan proses belajar mengajar, keaktifan guru dan siswa serta orangtua, kemudian menentukan hal apa lagi yang dapat digunakan untuk terus meningkatkan proses belajar mengajar.

4. A $($ Act $=$ Menindaklanjuti)

Tahap ini melakukan evaluasi total terhadap hasil sasaran dan proses dan menindaklanjuti dengan perbaikan-perbaikan. jika ternyata apa yang telah dikerjakan masih ada yang kurang atau belum sempurna, segera melakukan tindakan untuk memperbaikinya. Proses ini sangat penting artinya sebelum melangkah lebih jauh ke proses perbaikan selanjutnya.

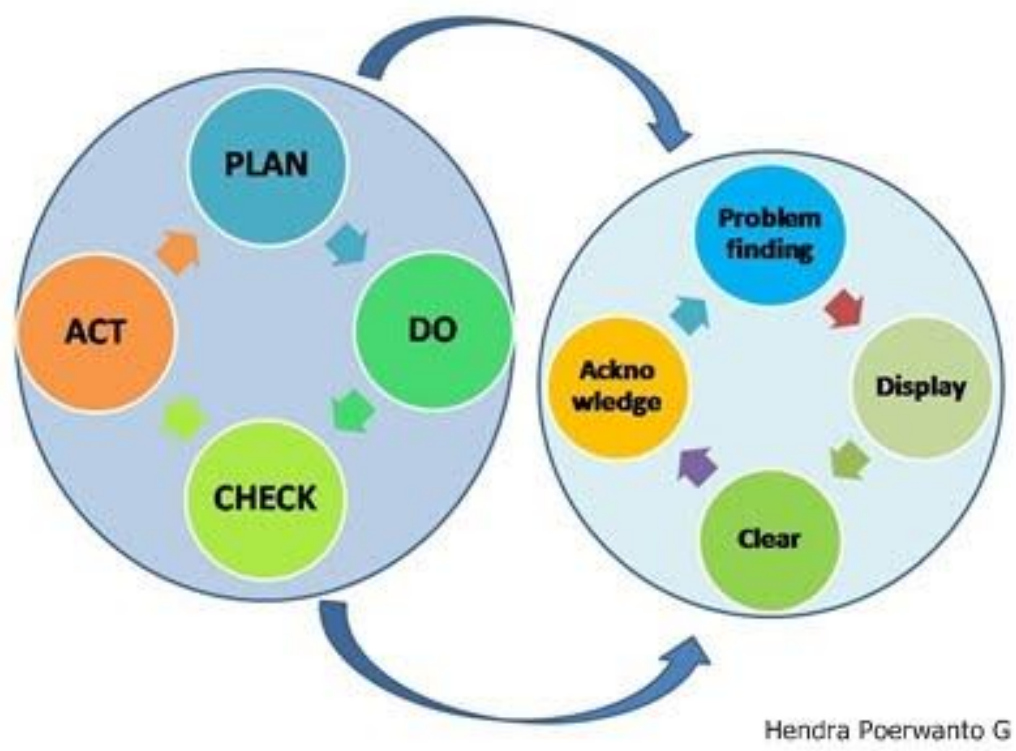

Gambar 2 Konsep PDCA dan Siklusnya

Gambar 2 menjelaskan bahwa hasil dari tahap-tahap proses PDCA kemudian digunakan untuk masukan bagi proses perencanaan lebih lanjut. Keempat proses yaitu Plan-Do-Check-Act $(P D C A)$ merupakan satu kesatuan siklus yang tidak dapat terputus dan saling berhubungan satu dengan yang lain.

\section{HASIL DAN PEMBAHASAN}

Implementasi E-Learning dengan Edmodo untuk untuk guru-guru sekolah dasar berdasarkan konsep PDCA. 


\subsection{Perencanaan}

Pada tahap ini dilakukan sosialisai, penentuan tujuan, analisa permasalahan pembelajaran, membandingkan Learning Management System (LMS) dan pengumpulan bahan serta mempelajari pembelajaran dengan e-learning sebagai tambahan atau suplemen dalam proses belajar mengajar saat ini. Gambar 3 ini menunjukkan proses pembelajaran konvensional di kelas, bukan karena guru yang tidak memiliki pengetahuan dan ketrampilan kekinian akan tetapi karena faktor tuntutan sistem dan kebiasaan[12].

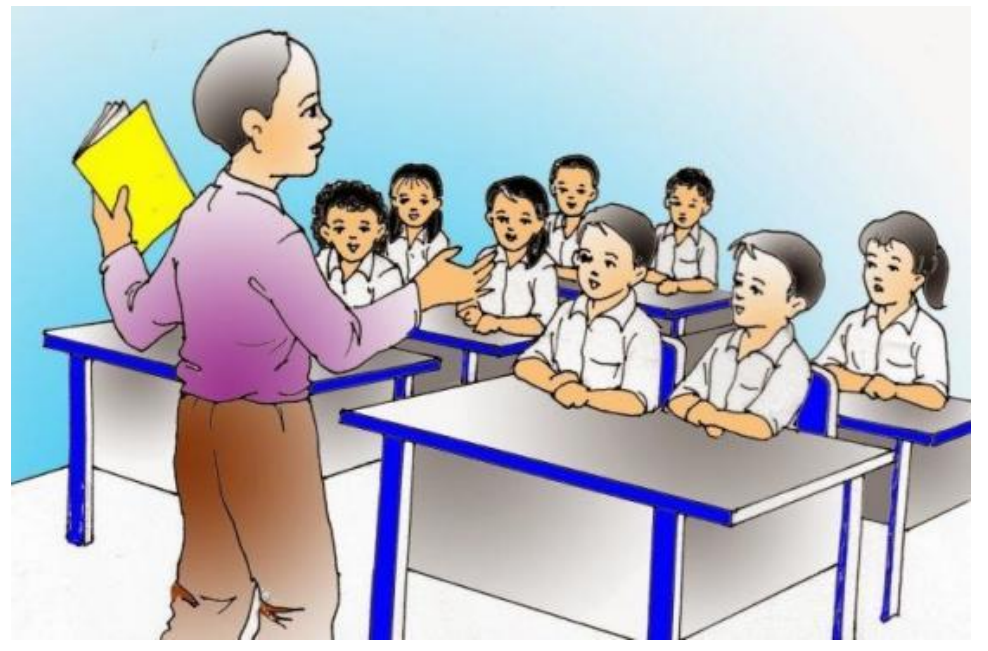

Gambar 3 Gambar Ilustrasi Pembelajaran Konvensional (Sumber : gudangilmu.com)

\subsection{Kerjakan}

Pada tahap ini mulai melakukan proses pelatihan yang diawali dengan pelatihan editing video dengan aplikasi Filmora yang nantinya untuk membuat bahan yang akan digunakan untuk memulai e-learning dengan Edmodo bagi 40 guru yang dilaksanakan di kantor Korwil Kec. Cawas, Klaten.

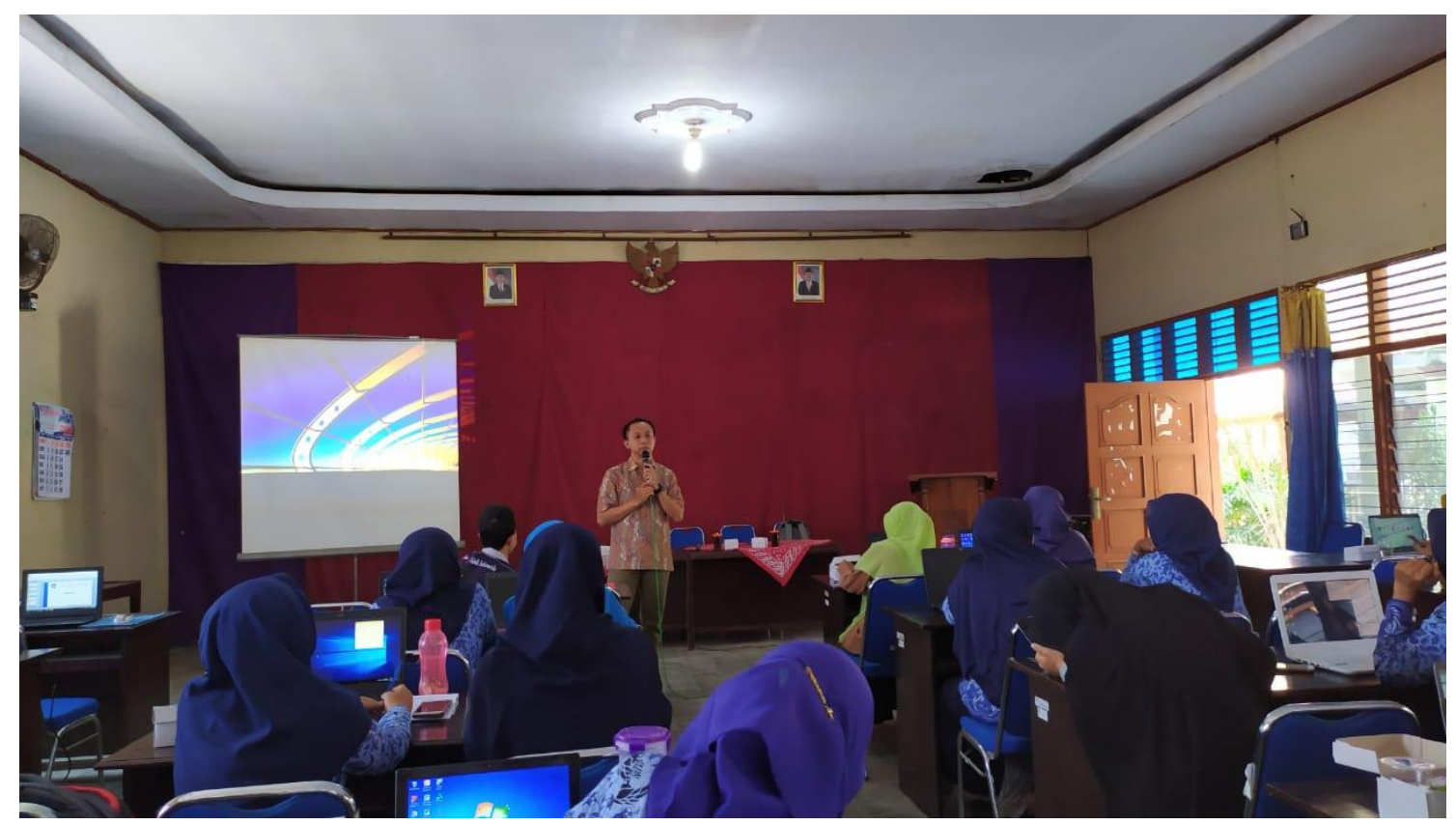

Gambar 4 Pelatihan editing video 


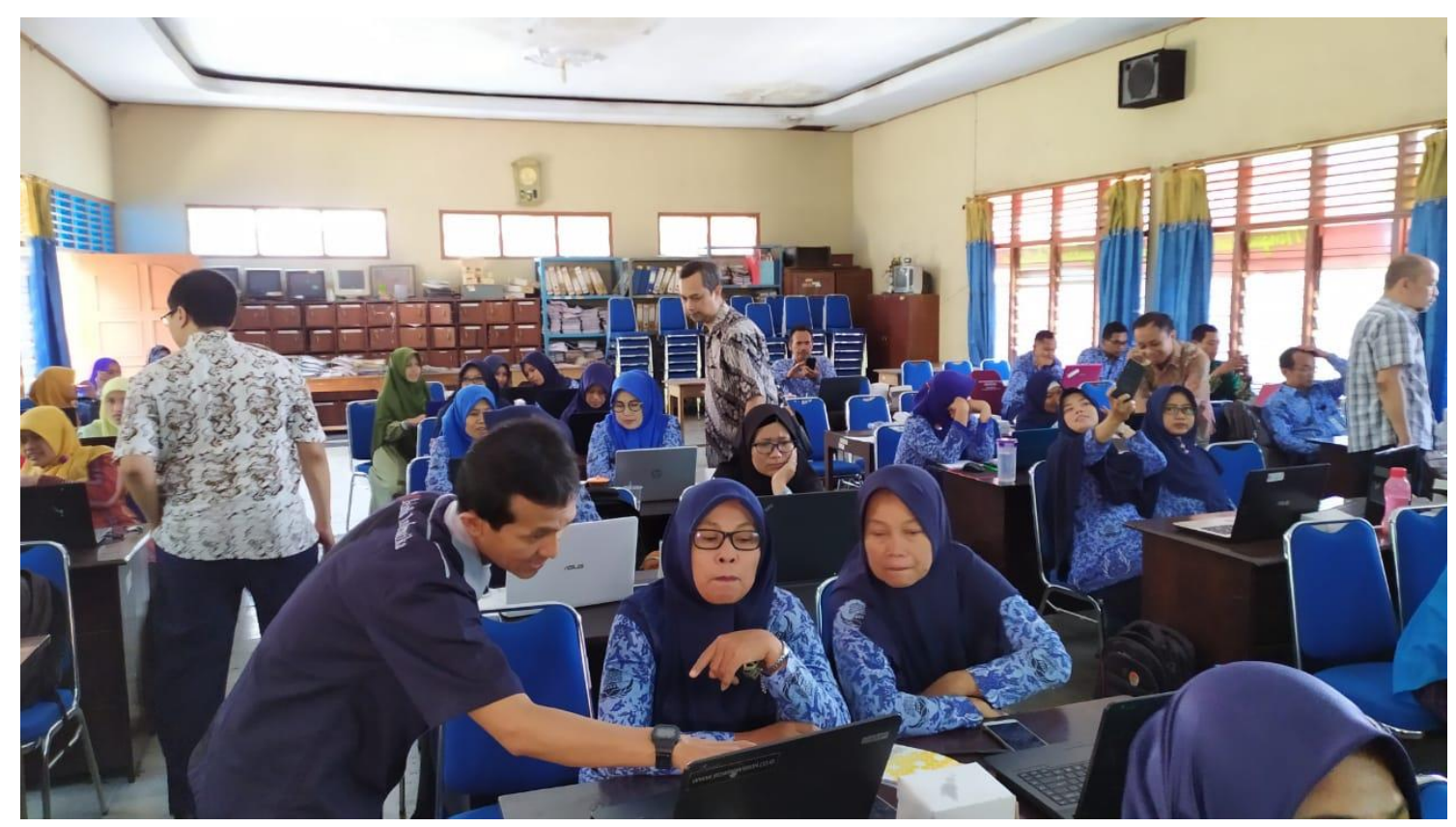

Gambar 5 Pendampingan pelatihan editing video

Gambar 4 dan gambar 5 menunjukkan kegiatan pelatihan video editing dengan aplikasi Filmora, para peserta belajar mulai instalasi software, menyiapkan bahan/material video yang akan diedit, belajar memotong video, memberi judul, menyisipkan suara dan terakhir membuat tulisan penutup / closing.

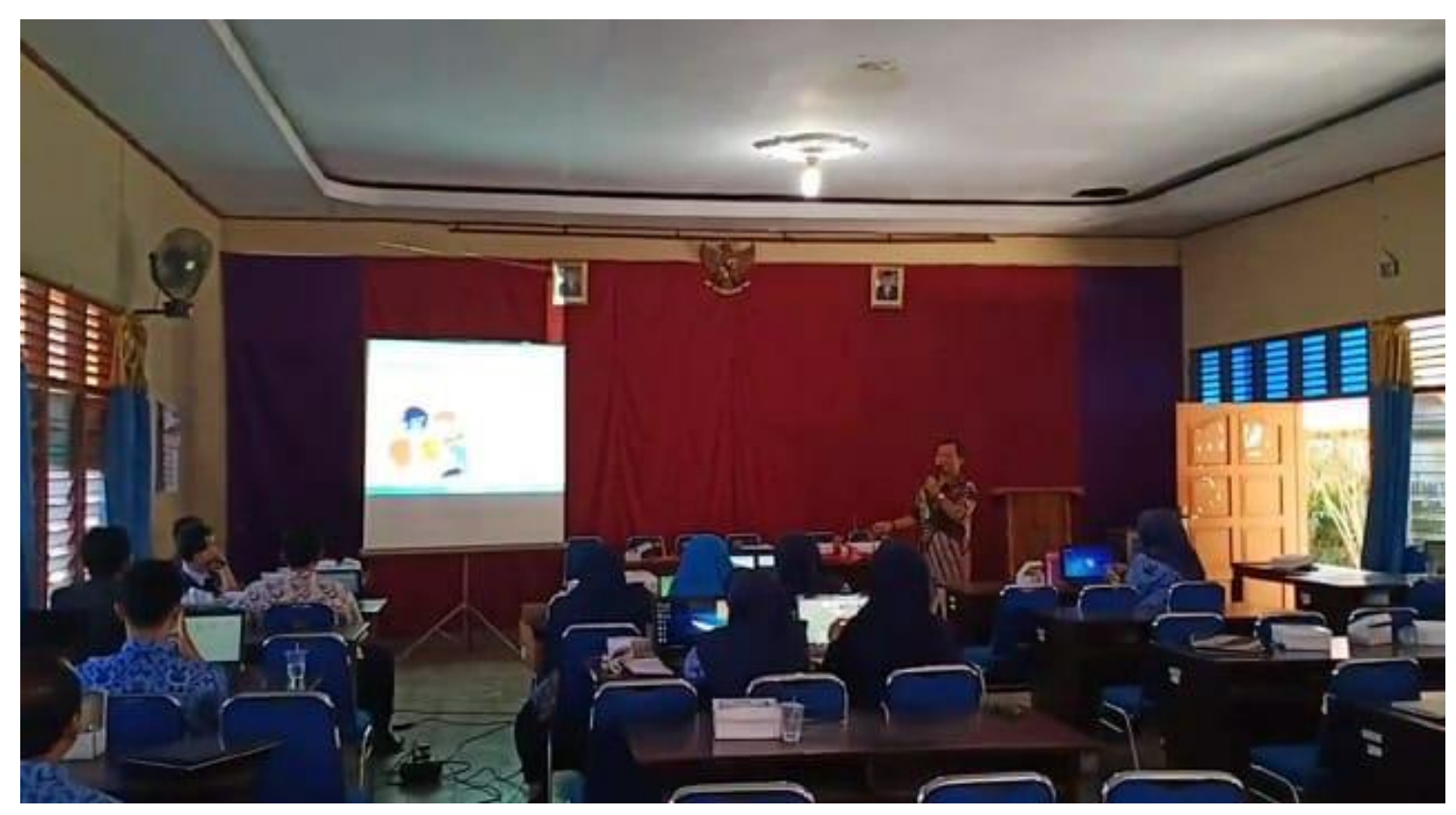

Gambar 6 Pelatihan e-learning dengan Edmodo 


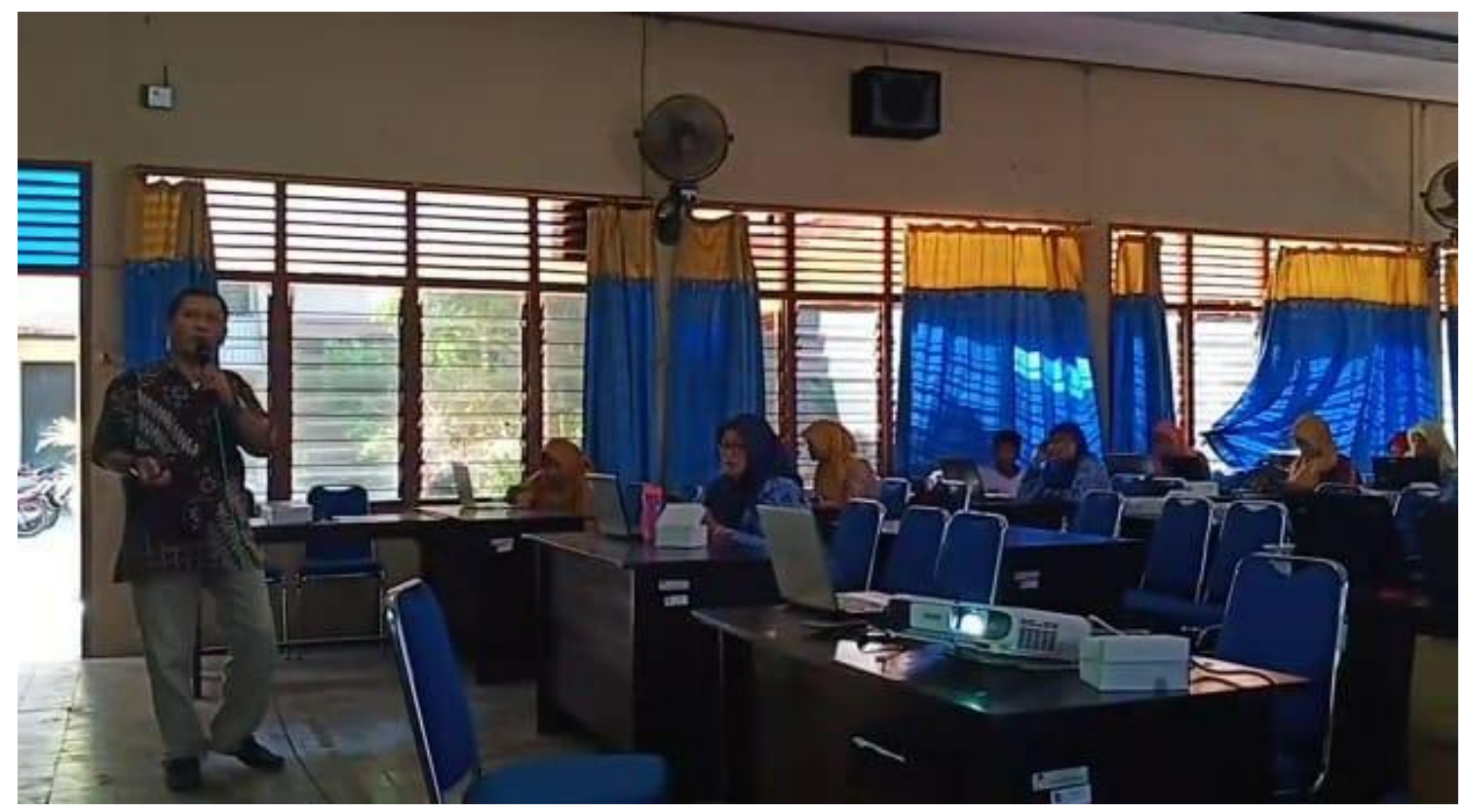

Gambar 7 Peserta pelatihan e-learning dengan Edmodo

Gambar 6 dan gambar 7 adalah proses pelatihan e-learning dengan Edmodo dengan materi untuk pengguna guru/teacher, pengguna siswa dan pengguna orangtua[13]. Materi yang disajikan sebagai berikut:

1. Pengertian Edmodo

2. Struktur / Framework Edmodo

3. Meng-Create Account Student pada Edmodo

4. Meng-Create Account Teacher pada Edmodo

5. Membuat Group di Edmodo, Invite Student

6. Membuat Note, Assignment, Quiz

7. Menambah Library, upload Content

8. Meng-Create Account Parent pada Edmodo

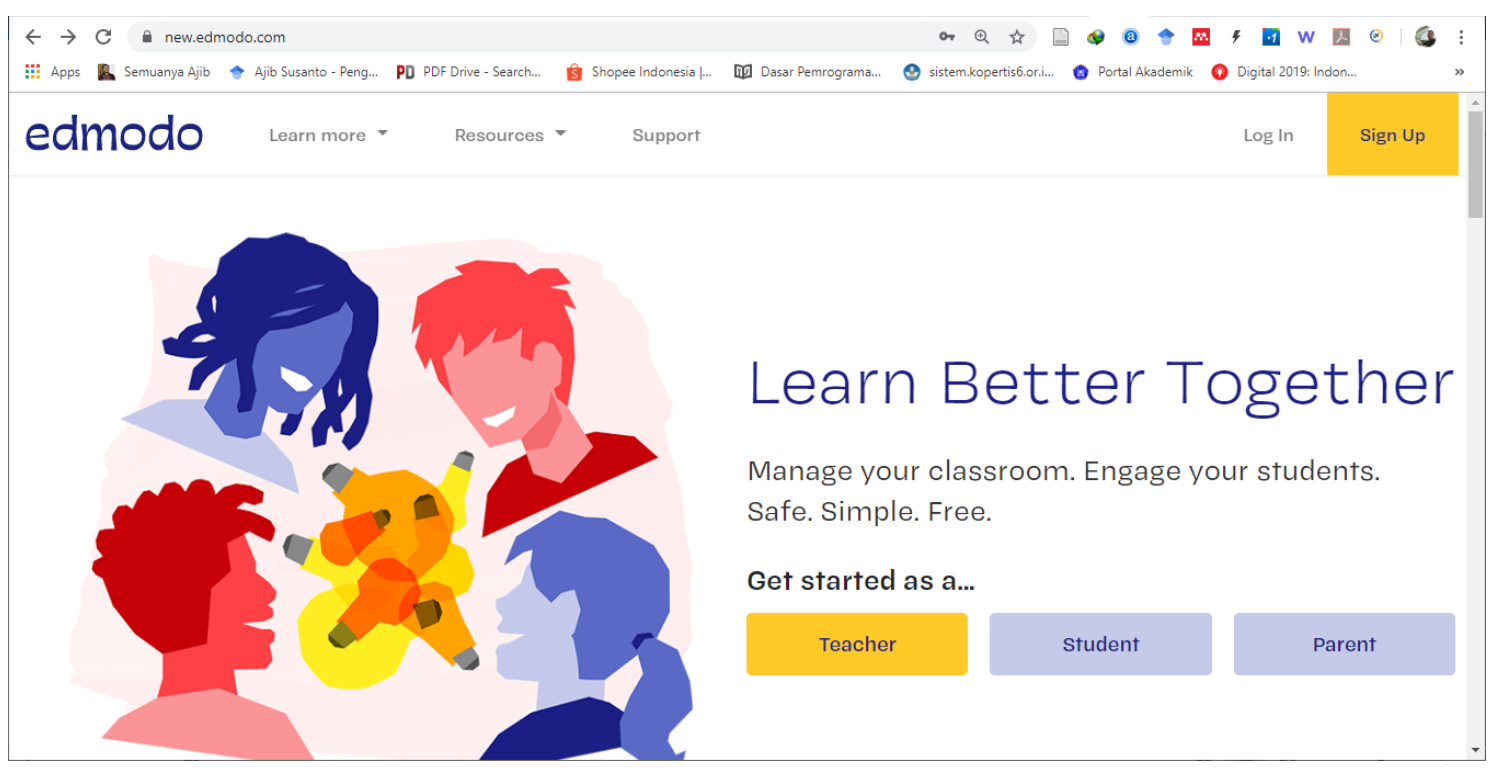

Gambar 8 Halaman e-learning Edmodo

Gambar 8 di atas menunjukkan halaman utama Edmodo yang terdiri dari tiga pilihan 
user yaitu teacher, student dan parent.

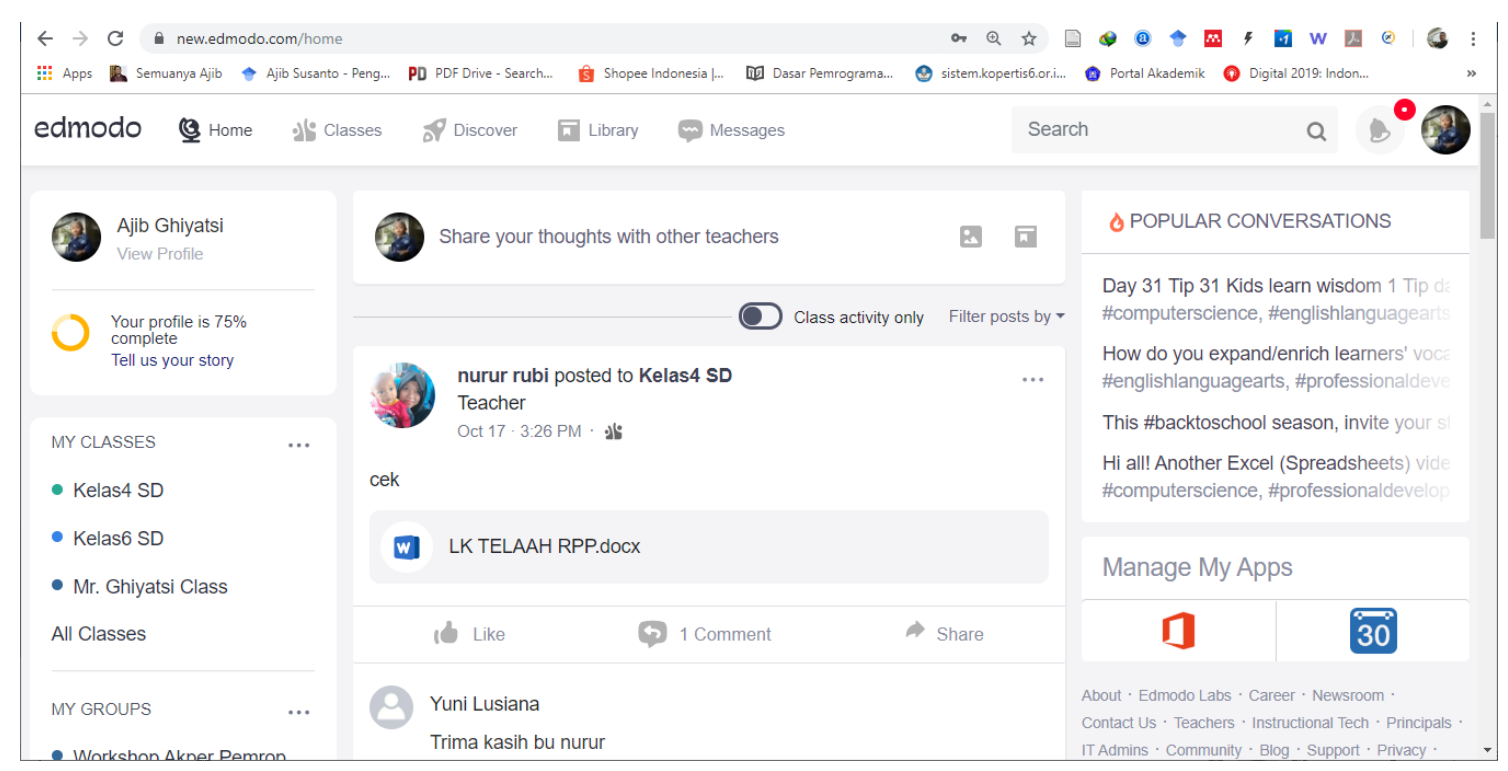

Gambar 9 Halaman Beranda Guru

Dari gambar 9 di atas menunjukkan halaman beranda guru dengan kelas yang dibuat dan diikuti (kolaborasi, terdapat unggahan dari guru lain untuk saling berbagi maerial untuk proses pembelajaran.

\subsection{Evaluasi}

Pada tahap ini memantau perkembangan implementasi e-learning dangan Edmodo yang dilakukan oleh guru, siswa dan orangtua. Hal yang dikerjakan adalah :

a. Mengamati jumlah respon dari pengguna pengguna baik guru, siswa dan orangtua.

b. Mengamati proses keaktifan dari pengguna Edmodo untuk masing-masing SD yang sudah menerapkan, masih berlanjut atau hanya sesaat saja.

c. Menganalisa respon atau tanggapan pengguna baik guru, siswa maupun orangtua apakah cenderung positif atau negative sehingga dapat dirumuskan langkah untuk mengantisipasinya.

\subsection{Menindaklanjuti}

Pada tahap ini dilakukan tindakan nyata sesuai rekomendasi atau laporan perkembangan setelah dilakukan evaluasi sehingga tujuan yang diharapkan dapat tercapai. Memulai kembali merencanakan, menganalisa dan menindaklanjuti yang disepakati sesuai hasil evaluasi sebelumnya.

\section{KESIMPULAN DAN SARAN}

Dari hasil implementasi e-learning dengan Edmodo memudahkan guru dalam memberikan materi kepada siswa dan orangtua baik dengan menggunakan smartphone yang dimiliki maupun dengan laptop/pc dapat dilakukan dimanapun dan kapanpun sehingga mampu melengkapi proses belajar mengajar di kelas. Sebagai upaya peningkatan e-learning ini untuk selanjutnya perlu diterapkan di seluruh SD di Kecamatan Cawas sehigga masing-masing sekolah akan menuju pada standart yang sama. 


\section{UCAPAN TERIMA KASIH}

Penulis mengucapkan terima kasih kepada Lembaga Penelitian dan Pengabdian Masyarakat (LPPM) Universitas Dian Nuswantoro yang telah memberikan dukungan melalui pendanaan dalam kegiatan pengabdian ini.

\section{DAFTAR PUSTAKA}

[1] Munir, "Dampak Teknologi Informasi Dan Komunikasi (Tik) Dalam Dunia Pendidikan Di Indonesia," Dampak eknologi Inf. dan Komun. Dalam Dunia Pendidik. di Indones., no. Teknol, pp. 1-13, 2010.

[2] A. Edi Winarno, "Mengatasi Empat Kendala Utama Dalam Rangka Optimalisasi Pembelajaran E-learning di Sekolah Dasar," 2017. [Online]. Available: https://www.kompasiana.com/mistered/59de35d463eae77800032ab2/mengatasi-empatmasalah-utama-dalam-rangka-optimalisasi-pembelajaran-e-learning-di-sekolahdasar?page=all. [Accessed: 05-Dec-2019].

[3] I. Bafadal, Peningkatan profesionalisme guru sekolah dasar: dalam kerangka manajemen peningkatan mutu berbasis sekolah, 5th ed. Jakarta: Bumi Aksara, 2009.

[4] A. Susanto, "Rekayasa sistem pengelolaan pembelajaran elektronik berbasis web," $J$. Dian, 2009.

[5] R. Sayekti, "The Implementation of E-learning System at UIN Sumatera Utara in Response to Technology Challenge in Education," J. Phys. Conf. Ser., vol. 970, no. 1, 2018.

[6] I. Widaningsih, Strategi Dan Inovasi Pembelajaran Bahasa Indonesia Di Era Revolusi Industri 4.0, 1st ed. Ponorogo: Uwais Inspirasi Indonesia, 2019.

[7] M. McCridle, "The Generation Map," $A B C X Y Z$, pp. 35-72, 2013.

[8] M. Bialik and C. Fadel, "Skills for the 21st century: What should students learn?," Cent. Curric. Resedisgn, no. May, pp. 1-13, 2015.

[9] A. Susanto, Pembelajaran Online dengan Edmodo. Semarang, 2015.

[10] Edmodo, "Edmodo," Edmodo, 2019. [Online]. Available: https://new.edmodo.com/. [Accessed: 05-Dec-2019].

[11] H. Poerwanto G, "Plan-Do-Check-Act (PDCA)," https://sites.google.com. [Online]. Available: https://sites.google.com/site/kelolakualitas/PDCA. [Accessed: 11-Oct-2019].

[12] A. Latip, "Saatnya Tinggalkan Metode Pembelajaran Konvensional," Kompasiana, 2018. [Online].

Available: https://www.kompasiana.com/altip/5c0db2cbab12ae71c8361e04/ saatnya-tinggalkanmetode-pembelajaran-konvensional?page=all. [Accessed: 05-Dec-2019].

[13] A. Susanto, E-Learning dengan Edmodo, 1st ed. Semarang, 2019. 